\title{
The Positive Effects of People-Plant Connection in Danish Work Settings
}

\author{
Anca $\operatorname{HUSTI}^{1 *}$, Jane THOMSEN $^{2)}$, Renate MULLER ${ }^{3)}$ and Maria CANTOR ${ }^{1)}$ \\ ${ }^{1)}$ Department of Horticulture and Landscape, University of Agricultural Sciences and Veterinary \\ Medicine, No. 3-5, Mănăștur Street, Romania \\ ${ }^{2}$ AgroTech Hoejbakkegaard Allé 21, Taastrup, Denmark, \\ ${ }^{3)}$ Department of Plant and Environmental Sciences, University of Copenhagen, Denmark \\ *)corresponding author, e-mail: anca.husti@gmail.com
}

BulletinUASVM Horticulture 72(1) / 2015

Print ISSN 1843-5254, Electronic ISSN 1843-5394

DOI:10.15835/buasvmcn-hort:10627

\begin{abstract}
Production of detailed information on the manner in which ornamental plants interfere with the features of the workplace, thus influencing the work environment and employee welfare is one of the purposes of this study. The research investigates how the interaction between people and plants influence the Danish work environment and how employees experience the use of plants. In order to investigate people-plant relationships by a qualitative case study was conducted at an administrative unit of a public organization from Copenhagen, Denmark. As data collection methods face to face semi-structured interviews and observations were used. Selection of indoor settings, cases and participants were purposefully sampled. Various characteristics were taken into account as selection criteria. The research results show that at the working environment ornamental plants are a component of the interior space. The use of ornamental plants by employees was made in various ways. Traditions, values, culture, history and organization policies influenced plant use by employees at work. The study revealed that plants affected the working environment and the employee's well-being. Participants in this study finds that ornamental plants left their mark on the workplace such as social climate, image organization and physical characteristics, on the individuals, considering their welfare, different moods and emotions.
\end{abstract}

Keywords: Danish work settings, employees, experiences, plants, productivity, well-being

\section{INTRODUCTION}

A topical issue in the contemporary context is the relationship between human well-being and the environment. Human health is influenced by the physical environments in a variety of ways such as psychological, behavioural, social and biological (Lawrence and Hartig 2001, Northridge et al., 2003).

The review of literature suggests that the way of living, work and many hours spent in indoor spaces (Hancock, 2002) has developed, for most of people, illnesses, syndromes, weaknesses, fears, and anxieties (Raffestin 1990, Wilson et al.,1998). Is no doubt that the presence of greenery can play a beneficial role to all: modern man has become aware that the contact with nature gives the nostalgia from the past and has become an urgent need to regenerate both body and spirit. The proximity of the green at work reduces, in fact, the sense of mental conditioning imposed by urban life (Agnes van den Berg et al., 2010; Jim and Chen, 2006; Orsega-Smith et al., 2004; Tyrväinen et al., 2003; Vries et al., 2003).

The physical environment in which the person lives exhibits a profound influence on his social behaviour (Bandura, 2001). Understanding the responses of psychological, physiological and social situation of humans related to plants may, therefore, constitute a valuable tool to improve the psychological conditions, both for the individuals, as to whole group. The relation between people and plants in work environments was studied by several researchers (Bringlismark et al., 2007; Dravigne et al., 2008; Shibata and Suzuki, 2002, 
2004), because it have become increasingly significant the information about the impact of various features on wellbeing of employees and working environment.

In recent decades the nature of work has changed significantly and the quality of working environment has become pivotal. Nowadays, employees need that company to provide a safe and ergonomic working environment for them, a work environment that enhances health, performance and productivity. This can be achieved also by including ornamental plants in the design of the workplaces.

Work environment being the place where employees spend most of the time, it may be beneficial to seek more knowledge about the relationship between people and plants, and to find which is the role of ornamental plants in the culture of the organization. It is essential that these environments to be improved.

The objective of the research was to identify experiences of greenery-connected with the indoor environment which were experienced by participants, but the main focus is in analyzing the outcomes that had employees on using plants and flowers in work environments from Denmark reflected on psychological, physical and social aspect.

\section{MATERIALS AND METHODS}

The present study is formed with using inductive research design. Saunders et al. (2003) affirmed that the inductive approach gives the chance to have more explanation of what is happening. Gray (2004) asserted that qualitative research is often associated with inductive research designs in which a range of methods are used to collect the data and explore the problem from different perspective.

The methodology used in this study was chosen the qualitative research, Grounded Theory and case study to explore experiences of people when use ornamentals in office settings. The choice of a case study research strategy had been attributed to a number of reasons. It offers the opportunity to "explain why certain outcomes may happen - more than just find out what those outcomes are" (Denscombe, 1998). Gray (2004) confirmed that a case study approach is particularly useful in revealing the casual relationships between the phenomenon and the context in which it takes place.
Selection of indoor settings, cases and participants were purposefully sampled. Perhaps nothing better captures the difference between quantitative and qualitative methods than the different logics that undergird sampling approaches. Qualitative inquiry typically focuses in depth on relatively small samples, even single cases $(n=1)$, selected purposefully. Quantitative methods typically depend on larger samples selected randomly.

Various characteristics were taken into account as selection criteria, the fundamental one: plants to be present in office spaces, full time employees in the office work environment and access to department. Selected employees for individual interview were four women, due to the fact that usually women are found in this type of work but also two men for diversifying the information. Qualitative studies generally permit the inquiry of only a few selected cases but in great depth and with attention to detail and context, thus enhancing the depth of the study (Patton, 2002).

For collecting data on social and organizational level of analysis, it was applied semi-structured face to face interviews with open-ended questions to the selected employees, observations and review of various documents. It was set up a general structure for the interviews by deciding in advance the main topics and subtopics. It was used semi-structured interviews because they provide a very flexible technique for small-scale research (Drever, 1995). It was developed an interview guide based on the interview used by Thomsen et al. (2011).

The respondents were interviewed individually at a quiet and comfortable location, in their private offices, under confidentiality, to give the participants the opportunity to express their views in a freeway and encourage them to talk. The interview was conducted using four themes which were introduced one theme at a time with several questions (Fig.1.). The following figure is a draft of the Interview guide design.

Observations of physical traces consisted of photographs, drawings, sketches, field notes were taken in offices but also annexes, where employees spend their working hours, and were conducted on working hours with a key informant: a selected employee who knows the history and culture of the workplace but also the spatial arrangement. 


\begin{tabular}{|c|l|l|}
\hline $\begin{array}{c}\text { Nr. } \\
\text { crt. }\end{array}$ & Topic & Question \\
\hline 1. & Demographic information & $\begin{array}{l}\text { What is your age? } \\
\text { What is your marital status? } \\
\text { How long have you worked here? }\end{array}$ \\
\hline 2. & $\begin{array}{l}\text { The plants/flowers that are } \\
\text { found in the workplace }\end{array}$ & $\begin{array}{l}\text { What is your personal workspace? It is a private, semi-private or an } \\
\text { open office? } \\
\text { Why do you think is important to have plants /flowers in a work space? }\end{array}$ \\
\hline 3. & $\begin{array}{l}\text { Wow plants and flowers affect } \\
\text { Wou }\end{array}$ & $\begin{array}{l}\text { What is the bad thing by having plants and flowers At work? } \\
\text { Do you feel the same when you see different plants? Color, size }\end{array}$ \\
\hline 4. & $\begin{array}{l}\text { Social aspect of having and } \\
\text { using plants/flowers at work }\end{array}$ & $\begin{array}{l}\text { Why do you think people have plants indoors ? } \\
\text { What is the difference between plants and other arts you have at work? } \\
\text { Which role can plants play in your community? }\end{array}$ \\
\hline
\end{tabular}

Fig.1. Interview guide design for semi - structured interview

Semi-structured individual interviews with selected employees took almost one hour. The interviews were made in the working hours, tape recorded (with the permission of the interviewee). The strategy of analysis has been carried out by achieving the steps required by the data emerging theory approach and the qualitative analysis software Nvivo version 10 . For data analysis were made several stages. The first step was to achieve transcripts, coding, categorizing different data sets and compare them. Similarities and differences in the categories formed were critically analyzed in order to find the real meaning of data.

\section{RESULTS AND DISCUSSION}

It was showed by the results of the study that the interaction of employees with plants was active or passive. The study revealed that ornamental plants had an impact on well-being of the employees and on working environment. In relation to individual well-being, plants affected emotions, feeling relaxed, happy and on physical well-being 'you feel calm, when you have an environment with plants', 'just make me feel happy'.

Regarding the working environment it was experienced that ornamental plants influenced the social climate, the image of the workplace and the interaction among the employees. This study has pointed out the preference of employees for offices with plants as opposed to offices without plants (Smith and Pitt, 2009). Participants prefer to have more plants in the work settings, because 'it's so gray, and white and sterile... and ...it's sad, it's too much gray and it...isn't friendly', 'that's the reason why companies have plants all over the place, makes people relaxed and welcome'.

Regarding the working environment it was experienced the preference of ornamental plants. Indoor plants in Danish work settings were regarded as important features, bringing so many benefits. The data revealed that employees seen that are more good and positive things to have plants at work then to bad ones : "I think it's ... great satisfaction", "I can't see any bad things", "most good things I would say ...about having plants at work"(Fig.2).

The results documented the interplay between people-plant relationships and other characteristics of the workplace. The analysis identified various factors which structure the use of plants in work settings. Organizational components was set out as a structuring factor due to the fact that the leadership of the department has allowed employees to personalize their workspace as long as it is done it with responsibility, bringing their own plants. In this way they can express their individuality. 
$\mathrm{X}$

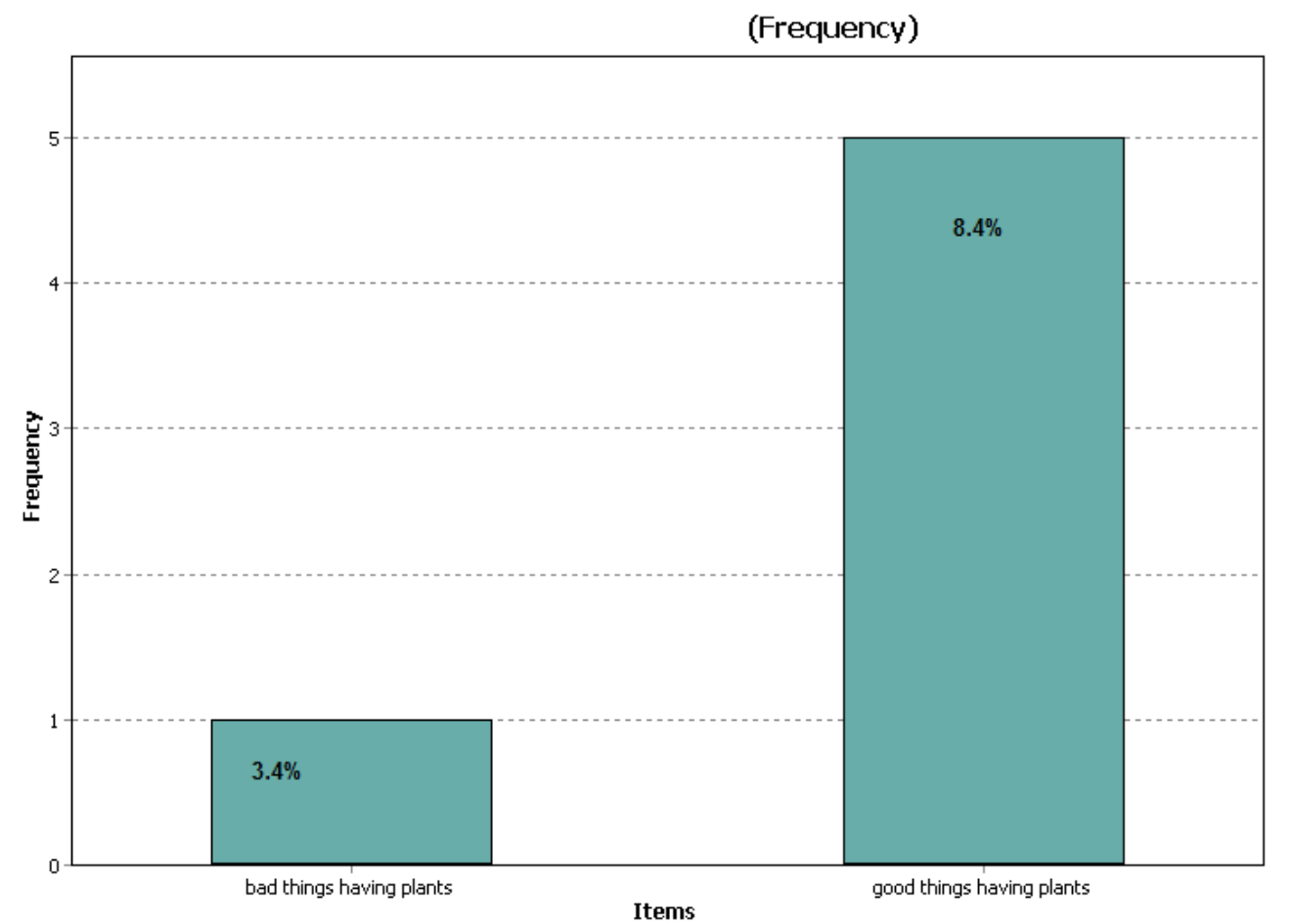

Fig.2. Rate of respondents answers at the item from topic 1

Note: According to the graphic X-axis represent the question answers, while Y-axis represent the frequency

$\mathrm{X}$

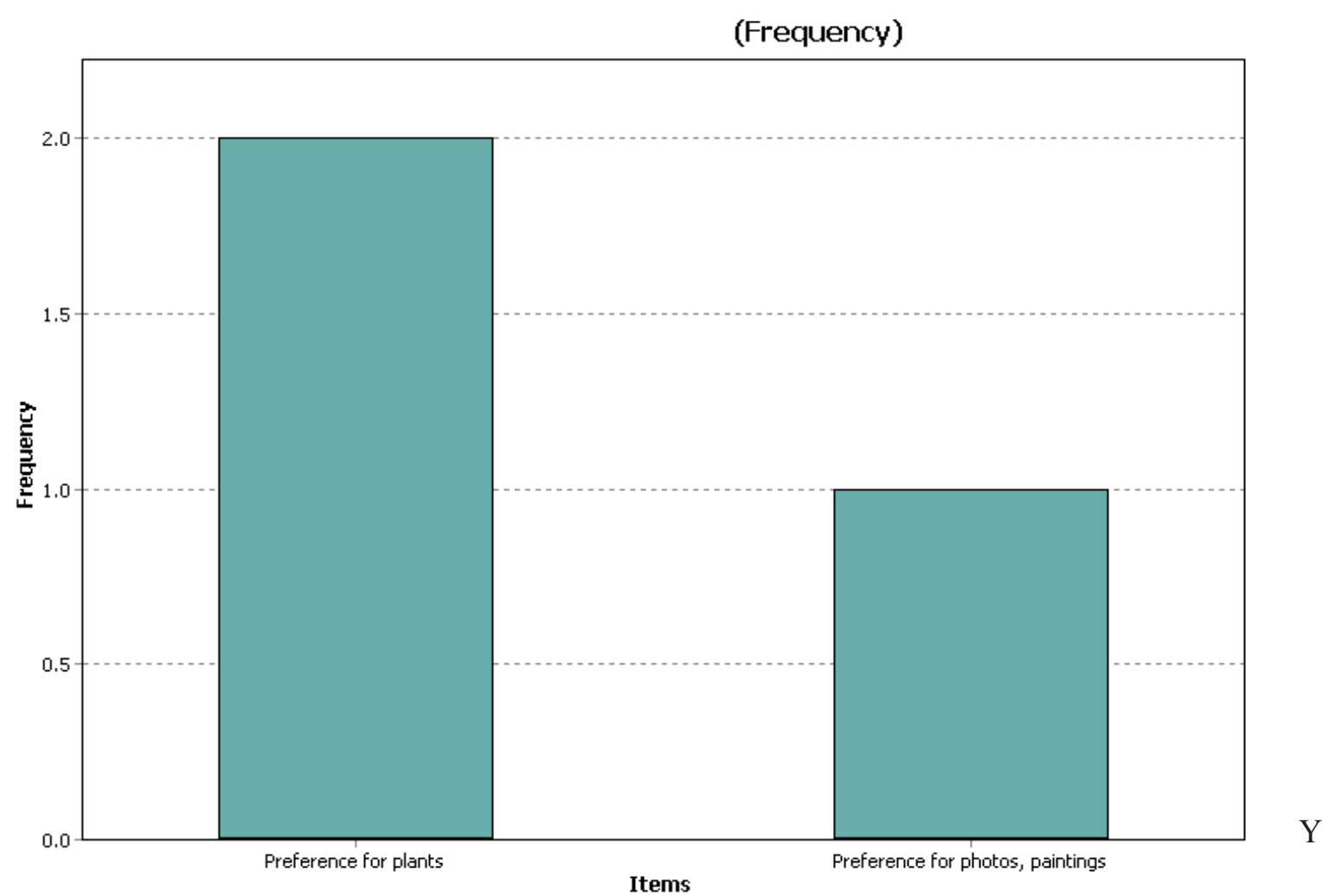

Fig.3. Rate of respondents answers at the item from topic 4

Note: According to the graphic X-axis represent the question answers, while Y-axis represent the frequency 
In Danish work environments using plants has become a cultural feature which is found also in the present investigation, where the employees assert that the management agreed to buy new plants to redecorate the space. Two employees are responsible for the maintenance of plants.

Plants were present in all 12 offices, even on the hallway, exhibiting a good image to department. In the investigation 49 indoor plants were found ranging from small to large sizes, different species and condition, 44 maintained, in a good shape, 5 poorly maintained.

The present research reveals and sustain the results of Thomsen et al.(2011) that culture and tradition are connected the use of various plants with religious events as Easter, Christmas or special occasions such as birthday, new colleagues or maternity leave. Workplace culture and values are the link between employees and experiences of using plants. It was observed in the department where the study was conducted a preference for succulents in offices, large plants such as Ficus spp., Dracaena spp., Chamaedorea, Beucarnea for meeting rooms, common room and hallway.

Due to the fact that plants are living, need care and it can be seen the life cycle, they are valued more than arts such as paintings or photos. According to the participant's answers, they prefer plants over paintings or photos (Fig.3).

Another meaning of workplace environment and values of plants is the fact that cannot be replaced by artificial flowers. They used terms like:" it grows, it blooms" "water them and take care"'" I don't know if they react to what you say to them, but if you put them into light, you can see that actually respond to the light and if you don't give them water they would not respond". Another meaning of workplace and values of plants is the fact that cannot be replaced by artificial flowers revealed by answers: "could be plastic plants, they are very common everywhere but you'll, you'll quite quickly you'll notice... something it's not right, so for me plastic plants would never do".

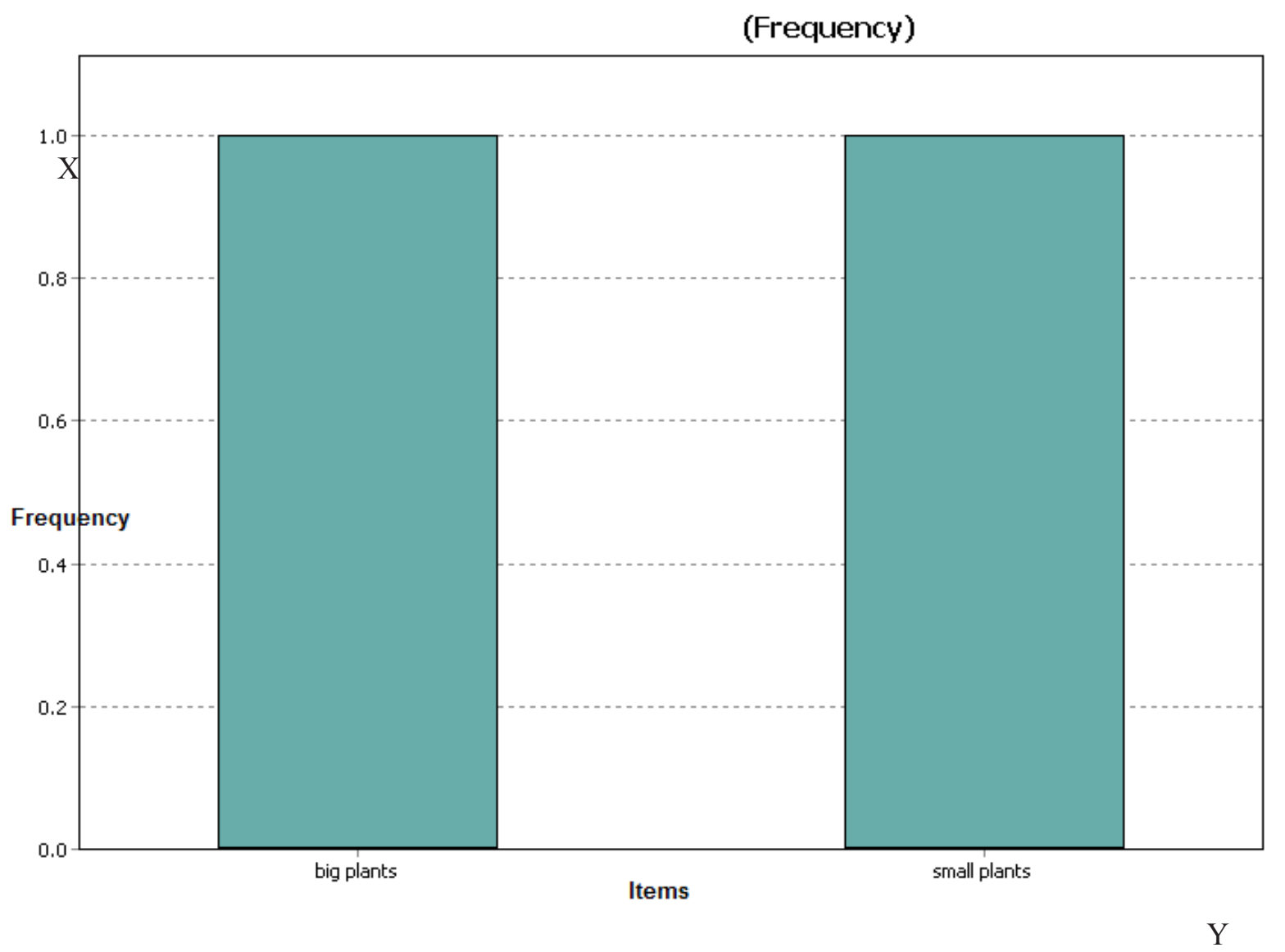

Fig.4. Rate of respondents answers at the item from topic 4

Note: According to the graphic X-axis represent the question answers, while Y-axis represent the frequency 
The link between employees and plants is evidenced, highlighted by the fact that they didn't throw out the plants even if were in bad conditions:" I find very difficult to throw up plants if they are still just the slightest alive, I keep them, it's, I think, it's so much a waste just to throw them out, it's difficult", and for them is not important the size of the plants (Fig.4).

The data revealed women misconceptions regarding men's preferences for plants, but in the same time the data showed that the preferences for plants is not gender specific. The study identified various reasons to have plants in office settings, from aesthetic values to social interactions and enhance well being.

The validity of this research was done by forming various methods to examine the situation from many angles and to support the validity of the conclusions.

\section{CONCLUSIONS}

Plants at workplaces were considered a meaningful item to create a restorative and positive atmosphere. At this level, it can be asserted that it is not concerning just the employee as an individual but include also the social aspect.

Overall, the study identified various reasons to bring plants in office settings. Plants at workplace were considered a meaningful item to create a restorative and positive atmosphere:" to me its pure, positive thing to have plants". Besides, plants in work settings design a new form of social environment, being a social phenomenon. At this level, it can be assert that is not concerning just the employee as an individual but include also the social aspect.

The actual study presents an example of connection between people and plants in a real life work environment from Denmark. To qualify the study beyond, a comparative case study should be taken, due to fact that the study was concentrated on Danish work settings and in different cultural context can have other impacts and forms.

The design and the framework of the present study provide support for this theoretical generalization in this study.

Acknowledgements. This paper was published under the frame of European Social Fund, Human
Resources Development Operational Programme 2007-2013, Project no. POSDRU/159/1.5/S /132765.

\section{REFERENCES}

1. van den Berg A, Maas J, Robert A, Verheij P, Groenewegenb $P$ (2010). Green space as a buffer between stressful life events and health, Social Science and Medicine 12031210.

2. Bandura A (2001). Social cognitive theory and clinical psychology. Oxford Elsevier Science.

3. Denscombe M (1989). The Good Research Guide. Buckingham: Open University Press.

4. Dravigne A, Waliczek TM, Lineberger RD, Zajicek JM (2008). The effect of live plants and window views of green spaces on employee perceptions of job satisfaction. HortScience

5. 43:183-187.

6. Drever E (1995). Using semi-structured interviews in small-scale research. A teacher's guide.

7. Edinburgh: Scottish Council for Research in Education.

8. Gray DE (2004). Doing Research in the Real World. Sage Publications, London.

9. Hancock T (2002). Indicators of Environmental Health in the Urban Setting. Canadian Journal of Public Health.

10. Jim CY, Chen WY (2006). Perception and attitude of residents toward urban green spaces in Guangzhou (China). Environmental Management, Vol. 38 No. 3.

11. Lawrence R, Hartig T (2001). Health, housing, and urban environments: Updating the agenda for research and practice. Open House Int. 26:3-7.

12. Northridge ME, Sclar ED, Biswas P (2003). Sorting out the connections between the built environment and health: A conceptual framework for navigating pathways and planning healthy cities. Journal of Urban Health. 80:556568.

13. Orsega-Smith E, Mowen AJ, Payne LL and Godbey G (2004). The interaction of stress and park use on psychophysiological health in older adults. Journal of Leisure Research, Vol. 36 No. 2.

14. Patton MQ (2002). Qualitative research and evaluation methods. Thousand Oaks, California.

15. Raffestin C, Lawrence R (1990). An ecological perspective on housing, health and well-being. J Sociol and Soc Welfare 17:143-160.

16. Shibata S, Suzuki N (2002). Effects of the foliage plant on task performance and mood. Journal of Environmental Psychology 22: 265-272.

17. Shibata S, Suzuki N (2004). Effects of an indoor plant on creative task performance and mood. Scandinavian Journal of Psychology 45:373-381.

18. Smith A, Pitt M (2009). Sustainable workplaces: Improving staff health and wellbeing using plants. Journal of Corporate Real Estate, Vol. 11, No. 1.

19. Thomsen JD, Sonderstrup-Andersen HHK, Muller R (2011). People-plant relationships in an office workplace: 
perceived benefits for the workplaces and employees. HortScience 45: 744-752.

20. Vries SD, Verheij RA, Groenewegen P, Spreeuwenberg P (2003). Natural environments-healthy environments? An exploratory analysis of the relationship between green space and health. Environment and Planning, Vol. 35 No. 10.

21. Wilson A, Seal JL, McManigal LA, Lovins LH, Cureton M, Browning WD (1998). Green Development: Integrating Ecology and Real Estate. 